\title{
A new model of lunar crust: asymmetry in crustal composition and evolution
}

\author{
Tomoko Arai ${ }^{1}$, Hiroshi Takeda ${ }^{2}$, Akira Yamaguchi $^{1,3}$, and Makiko Ohtake ${ }^{4}$ \\ ${ }^{1}$ Antarctic Meteorite Research Center, National Institute of Polar Research, 1-9-10 Kaga, Itabashi, Tokyo 173-8515, Japan \\ ${ }^{2}$ Department of Earth and Planetary Science, The University of Tokyo, Hongo, Tokyo 113-0033, Japan \\ ${ }^{3}$ Department of Polar Science, The Graduate University for Advanced Studies, 1-9-10 Kaga, Itabashi, Tokyo 173-8515, Japan \\ ${ }^{4}$ Planetary Science Department, Institute of Space and Astronautical Science (ISAS), Japan Aerospace Exploration Agency (JAXA), \\ 3-1-1 Yoshinodai, Sagamihara 229-8510, Japan
}

(Received May 7, 2007; Revised December 18, 2007; Accepted December 21, 2007; Online published April 9, 2008)

\begin{abstract}
Earlier models of lunar crustal formation as a simple flotation of ferroan anorthosites (FAN) do not account for the diverse crustal composition revealed by feldspathic lunar meteorites and granulites in the Apollo samples. Based on the integrated results of recent studies of lunar meteorites and global chemical and mineralogical maps, we propose a novel asymmetric crust model with a ferroan, noritic, nearside crust and a magnesian, troctolitic farside crust. Asymmetric crystallization of a primordial magma ocean can be one possibility to produce a crust with an asymmetric composition. A post-magma-ocean origin for a portion of the lunar crust is also possible and would account for the positive $\varepsilon_{\mathrm{Nd}}$ value for FAN and phase equilibria. The formation of giant basins, such as the South Pole-Aitken (SPA) basin may have significant effects on resurfacing of the early lunar crust. Thus, the observed surface composition of the feldspathic highland terrane (FHT) represents the combined results of magma ocean crystallization, post-magma-ocean magmatism and resurfacing by basin formation. The $\mathrm{Mg} /(\mathrm{Mg}+\mathrm{Fe})$ ratios, rock types, and mineral compositions of the FHT and the South Pole-Aitken basin Terrane (SPAT) obtained from the KAGUYA mission, coupled with further mineralogical and isotopic studies of lunar meteorites, will facilitate an assessment of the feasibility of the proposed crust model and improve understanding of lunar crustal genesis and evolution.
\end{abstract}

Key words: Moon, crustal evolution, asymmetry, lunar meteorites, KAGUYA.

\section{Introduction}

Our understanding of lunar origin and evolution have been significantly improved by post-Apollo orbital satellites, such as Galileo, Clementine and Lunar Prospector, and the discovery of lunar meteorites. Remote-sensing data have revealed that the chemical composition of the lunar global surface is heterogeneous. It has turned out that the region from which the Apollo missions obtained rock samples is unusually enriched in incompatible trace elements (ITEs), i.e. Th and U. Consequently, the Apollo samples are not representative of the global Moon.

Lunar meteorites are important ground truths for unexplored regions which have not been sampled by the Apollo and Luna missions because they were likely ejected from the lunar surface or subsurface by impacts at random locations on the Moon. About 104 pieces of lunar meteorites have been currently found in cold and hot deserts; these probably represent approximately 50 distinct locations on the Moon, considering simultaneous fall and/or ejection (e.g. Korotev and Zeigler, 2007). These lunar meteorites are composed of mare basalts, feldspathic rocks, and their mixtures, which cover nearly all the lithologies known from Apollo/Luna samples and remote-sensing data (Lucey et al., 2006). Most feldspathic lunar meteorites generally

Copyright (c) The Society of Geomagnetism and Earth, Planetary and Space Sciences (SGEPSS); The Seismological Society of Japan; The Volcanological Society of Japan; The Geodetic Society of Japan; The Japanese Society for Planetary Sciences; TERRAPUB. show low concentrations of ITEs relative to their Apollo counterparts and are therefore potentially derived from the farside highland. Studies of lunar meteorites and telescopic and global remote sensing have led to amendments to the classic magma ocean model that was proposed on the basis of the Apollo and Luna samples. This paper summarizes major advances in the understanding of the diversity of lunar crustal composition, proposes a new crust model, and discusses possible origins of the asymmetry in lunar crust composition.

\section{Earlier Studies of Lunar Crustal Evolution}

Lunar surfaces show two distinct geological units recognized by albedo differences-i.e., mare and highland. Since the mare regions were resurfaced by basaltic lava flows after the lunar crust had formed, the highland regions are the keys to understanding the composition and evolution of the early lunar crust. They are feldspathic in composition and older in age than the mare surfaces, and they are distinguished by numerous impact craters. Feldspathic highland samples were largely returned by the Apollo 15, 16 and 17 missions. Almost all feldspathic highland samples were heavily brecciated by numerous impacts and/or metamorphosed by shock heating. Thus, screening fragments of intact crustal rocks among the complex breccias based on combined petrologic/mineralogical/geochemical criteria is laborious, but extremely important (Warren, 1993). The selected "pristine" crustal rock fragments generally range 
in size from millimeters to microns, and more than half are less than 1 gram in mass. The few texturally altered crustal rocks are anorthositic, noritic or troctolitic cumulates. Compositionally "pristine" rocks (Warren and Wasson, 1977), which are not contaminated by impacted meteoroids, display a geochemical bimodality. One group (roughly half of the crustal rocks) has a higher modal abundance of plagioclase feldspar (> modal 90 vol\%) and lower $\mathrm{Mg} /(\mathrm{Mg}+\mathrm{Fe})$ ratios than the other group. Rocks belonging to the former group are designated as ferroan anorthosites (FAN), while those of the latter include $\mathrm{Mg}$-suite rocks plus some rocks enriched in alkali elements, termed alkali-suite rocks. There is another outstanding group, called KREEP, which is extremely enriched in alkalis and incompatible trace elements, such as K, rare earth elements (REEs) and P. They occur as impact melt rocks and basalts. The isotopic ages of these crustal rocks range from approximately 4.5 to approximately $4.0 \mathrm{Ga}$.

The origin of the lunar crust was initially argued based on the crustal rock fragments mentioned above. The global "magma ocean" model has been canonically used to effectively explain the chemical and mineral composition of FAN (Warren and Wasson, 1980; Warren, 1990). The earlier models were proposed to account for all the pristine highland rocks as magma ocean flotation cumulates (e.g. Wood, 1975). However, more recent models (Warren, 1990; Taylor et al., 1991; Papike et al., 1998) have considered FAN to be the only rock type that likely formed as a magma ocean cumulate and that $\mathrm{Mg}$-suite rocks and alkali-suite rocks represent intrusions that were subsequently emplaced into the FAN-rich crust, a conclusion based on the younger crystallization ages and the higher abundances of ITES in the $\mathrm{Mg}$-suite rocks and alkali-suite rocks in comparison to the FAN. Negative europium anomalies observed in mare basalts support the magma ocean model because they imply that the mare basalt sources were depleted in europium as a result of the flotation of massive plagioclase cumulates with positive europium anomalies in the magma ocean. Additional supporting evidence for the magma ocean hypothesis is the uniform trace-element pattern of KREEP-rich rocks, which suggests the presence of the residuum (urKREEP) of a single global magma ocean (Warren, 1985).

As an alternative model, Walker (1983) proposed "serial magmatism", assuming numerous local magmatic activities, including flows and plutons, to account for the petrogenetic diversity inferred from the various types of pristine crustal rocks. Wetherill (1981) proposed a model that the Moon is zoned-refined through the production of multiple regional magma chambers as the central impact melts generated during the biggest accretionary events. He claimed that it should be difficult to explain a heat source required to melt the Moon in the magma ocean hypothesis. In this model, low-density plagioclases concentrate upward within the multiple local impact melt pools, and a global layer of anorthositic crust is eventually generated through the cumulative effect. An anorthosite diapirism model has also been proposed as a modified version of the "multiple impact-melt-pool model" described above (Longhi and Ashwal, 1985). However, these alternative models have disadvantages in accounting for the geochemical bimodality of the FAN and the Mg-rich rocks. Shirley (1983) and Warren (1985) proposed models combining the "magma ocean model" and the "serial magmatism model", assuming a thin surface magma ocean plus an underlying convective crystalline mush, called "magmasphere" (Warren, 1985). These models were once considered to have an advantage in the thermal aspect, since the Moon can be mostly differentiated by the magmasphere without completely melting the differentiated volume. However, this is no longer the case because a recent theoretical modeling studies have shown that the initial Moon consisting of part of the primitive Earth and part of the impactor(s) would have been almost fully molten after the giant impact (e.g. Canup, 2004). A homogeneous mantle composition expected from the well-stirred mantle in the "magmasphere" model also seems to be also inconsistent with the compositional variety of crust and mantle inferred from the samples.

The magma ocean model has been the most popular model to reasonably account for both chemical and physical constraints, i.e. the mineral compositions of the FAN, the observed geochemical bimodality, the uniform KREEP composition and the proposed thermal state of the initial Moon. Further justification of the magma ocean model has been pending, awaiting the acquisition of additional samples and global elemental distribution.

\section{Recent Studies of Remote Sensing}

The recent remote-sensing data, such as those from Clementine and Lunar Prospector, have revealed that the globe-wide surface composition is extremely heterogeneous and the internal structure is not uniform. These findings indicate that the Apollo-era models of the lunar crustal evolution are too simplified to explain all this complexity. The following sections present the findings from remotesensing studies and relevant discussions that put significant constraints on the lunar crustal evolution.

\subsection{Complex surface compositions with the three ter- ranes}

The region from which the Apollo missions obtained rock samples is unusually enriched in incompatible and heat-producing elements, i.e. Th and U. Based on the distributions of the major element $(\mathrm{FeO})$ and trace element (Th), the global lunar surface has been classified into three distinct geologic terranes: (1) the Procellarum KREEP (K, REE, P) Terrane (PKT) enriched in FeO (nonmare $9.0 \mathrm{wt} \%$, mare $17.3 \mathrm{wt} \%$ ) and Th (non-mare $5.2 \mathrm{ppm}$, mare $4.9 \mathrm{ppm}$ ), corresponding to the central nearside in and around Ocean Procellarum and Mare Imbrium; (2) the South Pole-Aitken basin Terrane (SPAT) moderately enriched in $\mathrm{FeO}(5.7-10.1 \mathrm{wt} \%)$ and Th (1.0-1.9 ppm), referring to the region in and around the South Pole-Aitken (SPA) basin on the farside; (3) the Feldspathic Highland Terrane (FHT) with low FeO (4.2-5.5 wt\%) and Th (0.8$1.5 \mathrm{ppm}$ ), referring to the feldspathic highland other than the PKT and the SPA (Jolliff et al., 2000). The values of $\mathrm{FeO}$ and $\mathrm{Th}$ have been continuously improved with updated calibration methods (e.g., Gillis et al., 2004).

The presence of the PKT confined to the central nearside demonstrates that the traditional cross-cut model is not globally representative. At the same time, such an enhanced 
(16\% of the lunar surface) concentration of ITEs implies extensive differentiation of the globe- or semi-globe-scale magma ocean. However, it remains unknown whether this enrichment of ITEs is surficial or extends down to the crust and/or mantle. Since the PKT broadly overlaps the distribution of mare basalt, the origin of the PKT tends to be discussed in association with the lunar magmatic/thermal history. Although several models have been suggested (e.g., Ryder, 1991; Snyder et al., 1992; Hess and Parmentier, 1995; Haskin, 1998; Korotev, 2000; Wieczorek and Phillips, 2000; Zhong et al., 2000; Hess and Parmentier, 2001; Parmentier et al., 2002), the origin of the PKT remains unresolved.

In contrast with the PKT, the SPAT is far less enriched in Th and FeO. Warren (2004) proposed that the last dregs of the magma ocean enriched in the ITEs (called KREEP) would have failed to be excavated by the SPA impact because the SPA impact event preceded the timing of complete solidification of the magma ocean. The timing of complete magma-ocean solidification has been generally assumed to be within 100-200 Myr of the formation of the Moon (e.g. Taylor, 1982), but the date still remains debatable. Justification of the model is pending, awaiting acquisition of samples and the formation age of the SPA basin.

\subsection{Lateral compositional variation in the FHT}

Among the three terranes, the FHT most likely inherited the primary lunar crust. The FHT is located in part of the nearside southern hemisphere and almost the entire northern hemisphere of the farside. The study of the Clementine ultraviolet (UV)-visible (VIS) multispectral data revealed that large expanses of the lunar farside FHT have lower $\mathrm{FeO}$ abundance relative to the nearside FHT (Lucey et al., 1995, 1998, 2000). More precisely, the FHT is sub-divided into two regions: a Fe-poor, anorthositic FHT (FHT-A) in the central northern farside FHT, and a slightly more Ferich, outer FHT (FHT-O) in the neaside FHT, and eastern and western limbs of the farside FHT (Jolliff et al., 2000). Global mineral maps based on the Clementine UVVIS spectra (Lucey, 2004) display a heterogeneous mineral distribution in the FHT. Lucey (2004) analyzed less altered, immature surfaces, which cover approximately $5 \%$ of the entire lunar surface, at the $1-\mathrm{km}$ scale to estimate the mineral distribution and then interpolated the results for limited regions to fill in the rest of the unanalyzed area. The exposed immature materials analyzed in the study were generated by small craters, which generally mark the upper part of the crust (the top few hundred meters to a few $\mathrm{km}$ ). Thus, the mineral maps are only applicable to the lunar surface. This result showed that olivine is the sole mafic mineral in the farside FHT although its abundance is low, while orthopyroxene is dominant in the nearside highland without olivine. Orthopyroxene also occurs in the SPAT. Further, Lucey and Cahill (2006) applied the same technique to deduce the bimodal $\mathrm{Mg} /(\mathrm{Mg}+\mathrm{Fe})(=\mathrm{mg} \#)$ distribution (Mg-rich with $\mathrm{mg \#}>70$ and Fe-rich with $\mathrm{mg \#}<70$ ) of the feldspathic regions with $>85 \%$ plagioclase abundance. The mg\# map of the lunar surface shows a rough tendency for the northern farside FHT to be relatively Mg-rich, while the nearside, southern FHT is relatively Fe-rich. Although a tendency for a dichotomous mg\# variation in the FHT was

\section{Farside crust}

Nearside crust

\begin{tabular}{|c|c|c|}
\hline Froctolitic & Surface & Noritic \\
\hline Feldspathic & Upper crust & Feldspathic \\
\hline $\begin{array}{l}\text { More mafic } \\
\text { (Troctolitic) }\end{array}$ & Lower crust & $\begin{array}{c}\text { More mafic } \\
\text { (Noritic) }\end{array}$ \\
\hline
\end{tabular}

Fig. 1. Schematic crustal stratigraphy of the nearside and the farside, based on combined results of remote-sensing studies by Hawke et al. (2003) and Lucey (2004). A surface layer comprises mixture of a highly feldspathic, upper layer and a more mafic (noritic or troctolitic) lower layer. Thick SPA basin ejecta are present on top of the farside crust, and the thickness of the ejecta varies with the distance from the basin. It has been broadly suggested that a surface composition of the nearside FHT is relatively more ferroan than that of the farside FHT (Lucey, 2004).

presented, the true mg\# distribution of the FHT remains unknown. In summary, the Clementine reflectance spectral data have revealed an asymmetric surface composition of the FHT, showing that the nearside FHT is relatively $\mathrm{Fe}-$ rich, dominated by orthopyroxene and that the farside FHT is relatively $\mathrm{Mg}$-rich with olivine.

\subsection{Vertical compositional variation in the FHT}

In general, remotely sensed reflectance spectra can only constrain the surface composition. However, the reflectance spectra of deposits of large impact craters (called basins) have provided some insights into the vertical compositional variation in the FHT. Bussey and Spudis (2000) studied the ejecta composition of four multi-ring basins on the nearside (Orientale, Humorum, Nectaris, and Crisium). They showed that the crust around these basins is feldspathic down to depths of at least several tens of kilometers. Based on the compositions of the inner rings of these basins, it was further suggested that the lunar crust has a stratigraphy with a highly feldspathic $(\mathrm{FeO}<1 \mathrm{wt} \%)$ upper zone (at least 10-20 km deep) and a more mafic (FeO $10 \mathrm{wt} \%, \mathrm{Al}_{2} \mathrm{O}_{3}$ 18-22 wt \%) lower zone. Hawke et al. (2003) demonstrated that the highly feldspathic lithology is exposed at the inner rings of most nearside basins beneath the orthopyroxene-rich near-surface layer, utilizing telescopic near-infrared spectra and the Clementine multispectral images. Based on these observations, lunar crustal stratigraphy on the nearside was proposed with a noritic (anorthositic norite or noritic anorthositic) surface, a highly feldspathic upper crust, and a noritic (anorthositic-noritic or noritic anorthositic) lower crust (Fig. 1). The proposed nearside crust stratigraphy is consistent with the surface mineral distribution proposed by Lucey (2004). Since the noritic, surface composition of the nearside likely represents vertical mixing of the upper crust and the lower crust, the nearside lower crust is expected to be largely noritic.

Hawke et al. (2003) also showed that highly feldspathic lithology occurs as the inner rings of several basins of the farside. They proposed a crust stratigraphy similar to that of the nearside, with two marked differences from the nearside case: (1) a surface layer is largely covered by the SPA basin ejecta, and (2) the petrologic type of the surface layer and the lower crust is not specified. However, when it is pos- 
tulated that the olivine-rich surface composition of the farside FHT (Lucey, 2004) represents mixing of a feldspathic upper layer and a troctolitic lower layer, as in the case of the nearside crust stratigraphy, the farside crust stratigraphy can be inferred to be a troctolitic, surface layer with the SPA basin ejecta, a highly feldspathic upper crust and a troctolitic lower crust (Fig. 1).

Spectral analysis of central peaks of impact craters showed that the crustal compositions gradually increase in mafic content with depth from a predominantly highly feldspathic, upper crust to a more mafic-rich (approx. 75\% plagioclase) lower crust (Tompkins and Pieters, 1999), which is basically consistent with the crustal stratigraphy described above. However, petrologic differences within the crust through depths of approximately 5-30 km are not readily noticeable between the nearside and farside. This is partly because of biased selection of the studied central peaks. In order to eliminate color variations due to differences in viewing geometry occurring between orbits, these researchers studied central peaks for which the spatial resolution was better than $240 \mathrm{~m} /$ pixel and which fell within a single Clementine orbit. We suggest that more thorough studies of an unbiased selection of central peaks would substantiate the crustal stratigraphy proposed here.

\section{Recent Studies of Samples}

Recent studies of Apollo/Luna samples other than pristine rocks as well as lunar meteorites have revealed that the lunar feldspathic crust is far more diverse in terms of mineralogy, chemistry and isotopic composition than previously believed. The results of these studies are remarkably consistent with those of remote-sensing studies, strongly suggesting an asymmetry in lunar crustal composition. The important discoveries in the recent samples studies are summarized below.

\subsection{FAN is not representative of the lunar feldspathic} crust

Studies of pristine crustal rocks have demonstrated that FAN most likely represent the primitive lunar crust. However, mineralogical and geochemical studies of granulites/granulitic breccias, feldspathic regolith and feldspathic lunar meteorites indicate that the lunar crust does not solely consist of FAN. Granulites and granulitic breccias are crystalline rocks that are formed by recrystallization during prolonged annealing (Warner et al., 1977; Lindstrom and Lindstrom, 1986). They display granulitic textures with rounded polygonal grain shapes. Both granulites and granulitic breccias are present in Apollo and Luna samples and in lunar meteorites. Although these are not pristine because they have been contaminated by meteoritic siderophiles (Warner et al., 1977), their depletion of ITEs and ancient ages (3.9-4.3 Ga) indicate that granulites and granulitic breccias formed prior to the last major basinforming impact events and, therefore, originated from the early lunar crust (Warner et al., 1977). Granulites and granulitic breccias have been found mostly among Apollo 16, 17 and Luna 20 sites, distant from the PKT.

Granulites and granulitic breccias are moderately feldspathic, with $70-80 \%$ plagioclase, and are less feldspathic than FAN (generally $>90 \%$ plagioclase). They show a wide range of mg\# (49-79) for the mafic minerals and fall into two groups, magnesian $(\mathrm{mg \#}>70)$ and ferroan $(\mathrm{mg \#}$ $<70$ ) granulites (Lindstrom and Lindstrom, 1986). Since the ferroan granulites have mg\# values comparable to the range of FAN, the igneous precursors are probably associated with the FAN-suite rocks. In contrast, because the magnesian granulites $(\mathrm{mg} \# \approx 72-80,75$ in average) are significantly more $\mathrm{Mg}$-rich than FAN (mg\# = typically 50 65 ), their precursors can not be FAN. Based on the finding that the bulk compositions of the granulites all correspond to anorthositic norites with $25-29 \% \mathrm{Al}_{2} \mathrm{O}_{3}$, Lindstrom and Lindstrom (1986) proposed that the dominant precursors of the granulites are plutonic anorthositic norites, both ferroan and magnesian, rather than mixtures of FAN and $\mathrm{Mg}$-suite rocks among the pristine crustal rocks. Korotev et al. (2003) also demonstrated that the magnesian granulites can not be mixtures of FAN and Mg-suite rocks because the trace element characteristics (i.e. $\mathrm{Ti} / \mathrm{Sm}$ ) of the $\mathrm{Mg}$-suite rocks are inconsistent with those of the magnesian granulites. Thus, $\mathrm{Mg}$-rich feldspathic lithologies other than the known $\mathrm{Mg}$ suite rocks should exist.

Highland regolith and feldspathic lunar meteorites have additional clues by which to elucidate the lunar crustal composition. Feldspathic components in the Apollo 16 regolith and the Luna 20 regolith (average $\mathrm{mg \#} \approx 70$ ) are both more magnesian compared to FAN (Korotev et al., 2003). The plagioclase abundance is somewhat variable: the Apollo 16 feldspathic regolith is highly feldspathic $\left(31 \% \quad \mathrm{Al}_{2} \mathrm{O}_{3}\right.$, 89 vol\% plagioclase), and the Luna 20 feldspathic regolith is less feldspathic $\left(23 \% \mathrm{Al}_{2} \mathrm{O}_{3}, 68\right.$ vol\% plagioclase) (Korotev et al., 2003). Feldspathic lunar meteorites are also generally more magnesian $(\mathrm{mg \#}=60-73)$ than FAN with variable plagioclase abundance (76-89 vol\%). They are mostly noritic anorthosite, with variable amounts of $\mathrm{Mg}$ rich olivine (Korotev et al., 2003). Thus, feldspathic regolith and lunar meteorites both infer the presence of $\mathrm{Mg}$ rich, feldspathic rocks with variable plagioclase abundance in the lunar crust.

The higher mg\# values and the lower plagioclase abundance of granulite/granulitic breccia, feldspathic regolith and lunar meteorites compared to those of FAN indicate that the bulk feldspathic crust should be more magnesian and less feldspathic than FAN. The petrologic nature of granulites and feldspathic lunar meteorites further suggests that the lunar crust is noritic anorthosites or anorthositic norites. Korotev et al. (2003) recently estimated that the average composition of the feldspathic "upper" crust has $\mathrm{mg \#}=70$, with $28.5 \% \mathrm{Al}_{2} \mathrm{O}_{3}$, which corresponds to 83 vol\% plagioclase. The estimation should be only applicable to the "upper few kilometers" layer, which represents accumulated ejecta materials of multiple basin-forming events. The mg\# value $(\mathrm{mg \#}=70)$ is determined by sub-equal proportions of ferroan $(\mathrm{mg \#}=63)$ and magnesian components (Korotev et al., 2003). Hence, the FAN and the more magnesian feldspathic rocks may be equally important components in the lunar crust.

There seems to be no regional preference for the distribution of ferroan granulites and magnesian granulites in the Apollo 16 and 17 regions (Lindstrom and Lindstrom, 1986). In contrast, there is a substantial difference in modal abun- 
dance between the Luna 20 regolith (68\% plagioclase) and the feldspathic components in the Apollo 16 regolith (89\% plagioclase), despite their nearly identical mg\# (70-71) and common paucity of mare basalt components (Korotev et al., 2003). The distinct modal composition of the feldspathic regolith between the Apollo 16 and Luna 20 sites may be attributed to either lateral (regional) variations and/or vertical (depth) differences.

\subsection{Lunar meteorite Dhofar 489: Mg-rich feldspathic rocks from the farside $\mathrm{FHT}$}

Dhofar 489 is a 34.4-g lunar meteorite recently recovered in Oman. This feldspathic crystalline impact-melt breccia includes clasts likely of igneous origin - magnesian anorthosite (MAN) and spinel-bearing anorthositic troctolite (ST) (Takeda et al., 2006). Large (2.8 mm across) plagioclase grains of the MAN clast display twin lamellae, and the ST clast has a coarse-grained poikilitic texture. The MAN and ST are clearly distinct from the Apollo FAN rocks by their high mg\# (Fig. 2). Olivine is a dominant mafic mineral in both the MAN and the ST. The normative olivine abundance (approx. $20 \mathrm{vol} \%$ ) and the mg\# (78) roughly follow the proposed linear correlation between $\mathrm{mg \#}$ and olivine abundance among feldspathic lunar meteorites (Korotev et al., 2003). The MAN consists of 96.5 vol\% plagioclase and $3.5 \mathrm{vol} \%$ of olivine, whereas the ST is $72 \mathrm{vol} \%$ plagioclase and $25 \mathrm{vol} \%$ olivine, with minor pyroxene and spinel. Their olivine compositions show bimodal variations with $\mathrm{mg \#}=75-77$ for the MAN and 84-85 for the ST at the peak composition of each. Their distinct modal abundances and the bimodal mg\# distribution indicate that they represent two distinct rock types. The feldspathic compositions, relatively coarse grain sizes and olivine-dominated mineralogy imply that the two rock types possibly formed as cumulates by differentiation of a common magma body. The differences in their modal abundances and mg\# may reflect a different timing of crystallization or local heterogeneity. The proposed deep-crustal origin (a few tens of kilometers deep) of the ST (Takeda et al., 2006) suggests that the ST originated from the lower crust.

Feldspathic lunar meteorites are generally considered to come from the farside FHT based on their low contents of ITEs. Because feldspathic lunar meteorite breccias would have "sampled" an area of considerable extent, it is likely that they would have incorporated ITE-rich KREEP material unless they were formed far from the PKT. Since lunar meteorites represent random sampling of the lunar surface, the more extensive area of FHT on the farside compared to the nearside favors the preferential derivation of lunar meteorites from the farside. Origin on the farside FHT seems most likely for Dhofar 489 based on several lines of evidence. The extremely low $\mathrm{FeO}$ and Th contents, lowest of all the feldspathic lunar meteorites, and the high mg\#, highest of all the feldspathic lunar meteorites, as well as the presence of olivine-dominated feldspathic rocks (Takeda $e t$ al., 2006) are consistent with the farside FHT composition, which is low in $\mathrm{FeO}$ and $\mathrm{Th}$ content, relatively $\mathrm{Mg}$ rich and troctolitic (Lucey et al., 1995; Lawrence et al., 2003; Lucey, 2004; Lucey and Cahill, 2006). The positive correlation between $\mathrm{mg \#}$ and olivine abundance in the feldspathic lunar meteorites (Korotev et al., 2003) can be

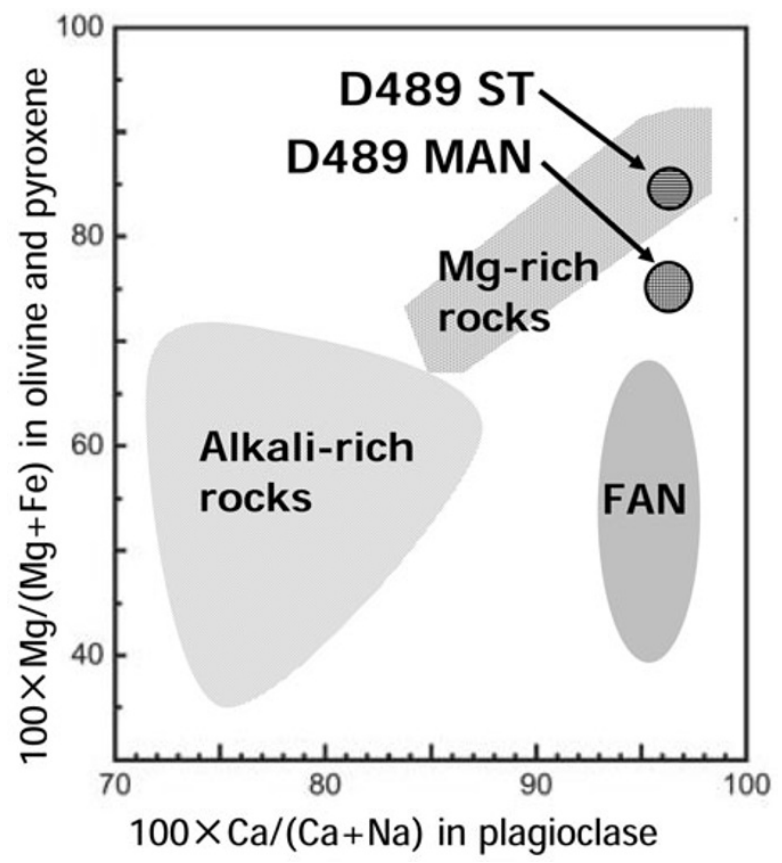

Fig. 2. Plot of $\mathrm{Mg} /(\mathrm{Mg}+\mathrm{Fe})$ atomic ratio $(=\mathrm{mg} \#)$ in mafic minerals versus $\mathrm{Ca} /(\mathrm{Ca}+\mathrm{Na})$ atomic ratio $(=\mathrm{An})$ in plagioclase. The MAN (magnesian anorthosite) and ST (spinel-bearing anorthositic troctolite) clasts of Dhofar (D) 489 are plotted against the pristine crustal rocks from Apollo samples. The MAN is plotted outside of compositional range of the Apollo FAN (ferroan anorthosites).

linked with the dichotomous compositional variation of the FHT with the troctolitic, Mg-rich farside and the noritic, Ferich feldspathic nearside (Lucey, 2004; Lucey and Cahill, 2006). Lastly, the ancient Ar-Ar age (4.23 Ga) (Takeda et al., 2006), which predates those of most Apollo highland samples (approx. 3.8-4.0 Ga) (Tera et al., 1974; Nyquist, 1977) implies that Dhofar 489 likely came from regions distant from the large, young basins sampled by Apollo missions. Thus, we favor the origin of a farside FHT (probably FHT-A) for Dhofar 489, although there is a counter opinion that it could come from somewhere deep in the feldspathic crust (Korotev et al., 2006). The simultaneous occurrence of the MAN and the ST in the same meteorite suggests that both rock types must occur more frequently on the lunar farside than appears to be the case for the nearside where minor spinel troctolites have been reported in the Apollo samples (Dowty et al., 1974; Ma et al., 1981). Consequently, Dhofar 489 suggests a significant hemispheric dichotomy in crustal rock types.

\section{$4.3 \varepsilon_{\mathrm{Nd}}$ conundrum of FAN}

Recent studies of neodymium (Nd) isotopes cast skepticism on the canonical FAN origin as floated cumulates of the primordial magma ocean. The $\varepsilon_{\mathrm{Nd}}$ is a useful indicator to evaluate how the ${ }^{143} \mathrm{Nd} /{ }^{144} \mathrm{Nd}$ ratio differs from values evolving over time in a "chondritic" reservoir, denoted

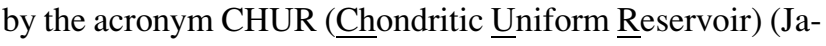
cobsen and Wasserburg, 1984). It is defined as

$\varepsilon_{\mathrm{Nd}}=\left[\left({ }^{143} \mathrm{Nd} /{ }^{144} \mathrm{Nd}\right)_{\text {rock }} /\left({ }^{143} \mathrm{Nd} /{ }^{144} \mathrm{Nd}\right)_{\mathrm{CHUR}}-1\right] \times 10^{4}$

Nonzero $\varepsilon$ values mean that $\mathrm{Sm}$ and $\mathrm{Nd}$ have been fractionated at some time in the distant past and that the iso- 
tope ratios have evolved to values either greater $(+)$ or less (-) than the "chondritic" evolutionary curve. If the enrichment of light rare earth elements (LREE), which is characteristic of the FAN, was engendered during crystallization from a magma ocean with initially chondritic relative REE abundances, the $\varepsilon_{\mathrm{Nd}}$ should have a value of zero or-more likely - a negative value. This would be due to tendency of pyroxene crystallization to enrich LREE over heavy REE as the magma ocean evolves towards plagioclase saturation (i.e., flotation of FAN) (e.g. Snyder et al., 1992). However, positive initial $\varepsilon_{\mathrm{Nd}}$ values have been reported for several Apollo 16 FAN rocks: 0.9 \pm 0.5 for 60025 (Carlson and Lugmair, 1988), $0.8 \pm 1.4$ for 67215 (Norman et al., 2002) and $3.1 \pm 0.9$ for 62236 (Borg et al., 1999). These positive initial $\varepsilon_{\mathrm{Nd}}$ values infer that the FAN should be derived from a reservoir having a higher $\mathrm{Sm} / \mathrm{Nd}$ ratio than chondritesi.e. a more LREE-depleted fractionated reservoir. No conventional magma ocean model predicts LREE depletion in the magma ocean evolution. A negative initial $\varepsilon_{\mathrm{Nd}}$ value has been recently reported for an anorthositic clast in the Yamato-86032 feldspathic lunar meteorite (Nyquist et al., 2006). The presence of anorthositic rocks with both negative and positive $\varepsilon_{\mathrm{Nd}}$ values implies that the lunar crust is of two distinct origins: one formed from the primordial magma ocean and the other from remelting of mafic cumulates after the magma ocean solidification.

Norman et al. (2002) speculated that the bulk-Moon composition might have a sub-chondritic $\mathrm{Nd} / \mathrm{Sm}$ ratio to engender the LREE-depleted primordial magma ocean. However, this speculation seems unrealistic because the magnitude of the $\mathrm{Ce} / \mathrm{Yb}$ fractionation associated with the source $\mathrm{Sm} / \mathrm{Nd}$ ratio in this model seems too extensive unless the bulk-Moon composition is extremely depleted in LREE and other incompatible trace elements relative to other refractory elements, such as $\mathrm{Al}$ and $\mathrm{Ca}$ (Warren, 2004). Norman et al. (2002) also pointed out that the positive $\varepsilon_{\mathrm{Nd}}$ could result if the canonical value of CHUR-Nd was not representative, at least for lunar material, since the definition of $\varepsilon_{\mathrm{Nd}}$ to be positive or negative highly depends on the CHUR-Nd value (Norman et al., 2002). In fact, ${ }^{143} \mathrm{Nd} /{ }^{144} \mathrm{Nd}$ for the HED (howarditeeucrite-diogenite) parent body reported by Nyquist et al. (2006) is higher than their interlaboratory-adjusted value for CHUR (Jacobsen and Wasserburg, 1984). The $\varepsilon_{\mathrm{Nd}}$ paradox remains a major point of debate not only for the lunar crustal evolution but also for the origin of the Moon. Future $\varepsilon_{\mathrm{Nd}}$ studies of Dhofar 489 will provide a clue to resolve this conundrum.

\section{Asymmetric Crust Model}

Recent studies of lunar meteorites and remote sensing strongly suggest an asymmetry in lunar crustal composition and stratigraphy of the two hemispheres. Here, we propose a new crust model and provide the rationale behind our model in comparison to previously proposed models.

Korotev et al. (2003) suggested a possible crustal configuration of a ferroan anorthositic upper layer and a magnesian, slightly more mafic lower layer by linking the FAN and the magnesian feldspathic rocks as the precursor of the magnesian granulites with the remotely sensed crustal con- figuration (Tompkins and Pieters, 1999; Bussey and Spudis, 2000; Hawke et al., 2003). This model seems to be consistent with the simultaneous occurrence of the magnesian and ferroan granulites within the Apollo samples and the feldspathic lunar meteorites. However, it contains several problems and uncertainties. Firstly, the difference in mg\# between the upper crust and the lower crust can not be resolved by current remote sensing. It would be equally reasonable to assume that the upper layer is more magnesian than the lower one or that both layers have comparable mg\# values. Secondly, some mafic-rich feldspathic rocks with $70-80$ vol\% plagioclase are present among the Apollo FAN collection (Wieczorek et al., 2006). Thus, the lower mafic-rich layer can be similarly ferroan to the upper FAN layer. Thirdly, there is no correlation between mg\# and modal abundance of plagioclase in the feldspathic rocks from the Apollo/Luna, samples and lunar meteorites. Both the ferroan and magnesian granulites show comparable modal abundances (70-80 vol\% plagioclase).

Dhofar 489 has provided important clues for resolving the uncertainty and the questions addressed above. Analyses of Dhofar 48 first verified that crystalline magnesian feldspathic rocks (MAN and ST) are present within the lunar crust. The presence of such magnesian feldspathic rocks has been implied as a precursor lithology of the magnesian granulite (Lindstrom and Lindstrom, 1986; Korotev et al., 2003), but any of the pristine crustal rocks found among the Apollo samples were not suitable as the precursor. Magnesian anorthosites and spinel troctolites reasonably correspond to the precursor of the magnesian granulite. The mg\# (76 in average) and the modal abundance (70-80 vol\% plagioclase) of the magnesian granulite broadly match those of the mixture of the MAN (mg\# = 75-77, $96.5 \mathrm{vol} \%$ plagioclase) and the ST (mg\# = 84-85, 72 vol\% plagioclase). Therefore, the magnesian granulite may represent the average composition of the crust dominantly composed of the MAN and the ST. The bulk-rock $\mathrm{Al}_{2} \mathrm{O}_{3}$ content $(28.1 \mathrm{wt} \%$ mass-weighted mean) of Dhofar 489 is close to the average modal composition of the "upper" crust (Korotev et al., 2003). The deep-crust origin for the ST (a few tens of kilometers deep) (Takeda et al., 2006) further led to an inference that the ST originated from the lower crust and the MAN from the upper crust in the source region.

The co-existing MAN and ST further infer a possible spatial and genetic connection between FAN and ferroan anorthositic norites/noritic anorthosites in the Apollo samples. The moderately low abundance of plagioclase $(70$ $80 \mathrm{vol} \%$ ) of the ferroan granulite can be more reasonably explained by the mixture of these two types of ferroan feldspathic rocks than by FAN itself. The nearside crustal stratigraphy of the feldspathic upper crust and the noritic lower crust (Hawke et al., 2003) is remarkably consistent with the proposed link between FAN and ferroan, slightly more mafic rocks (dominantly norites/noritic anorthosites). Thus, the lunar crust consists of a magnesian feldspathic portion and a ferroan feldspathic portion, as evidenced by the presence of the magnesian and ferroan granulites. Magnesian granulites and ferroan granulites were probably assembled by large impacts that penetrated to the magnesian portion and the ferroan portion of the crust, respectively 
Farside

Nearside

Magnesian crust

Ferroan crust

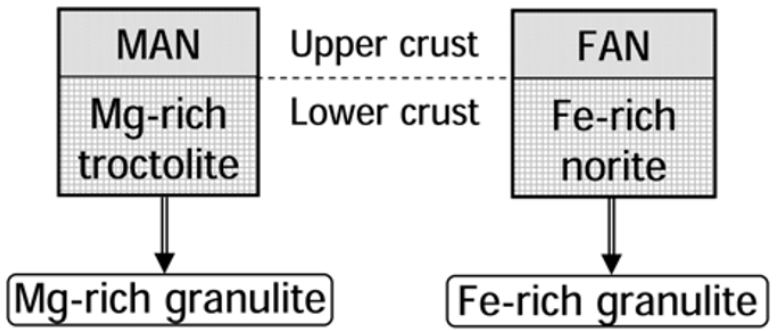

Fig. 3. Schematic figure of lunar feldspathic crust with dichotomous compositions, as inferred from lunar meteorites and the Apollo granulites. Precursors of ferroan granulites and magnesian granulites correspond to a ferroan portion and a magnesian portion of the crust, respectively. The magnesian portion comprises a magnesian anorthositic, upper crust and a magnesian troctolitic lower layer (anorthositic troctolite or troctolitic anorthosite). The ferroan crust comprises a ferroan anorthositic, upper layer and a ferroan noritic lower layer (anorthositic norite or noritic anorthosite). A provenance of the nearside FHT for the FAN and a possible origin of the farside FHT for the MAN and ST in Dhofar 489 suggest a ferroan crust on the nearside and a magnesian crust on the farside.

(Fig. 3). Combined with the crustal zonation indicated by remote sensing (Bussey and Spudis, 2000; Hawke et al., 2003), where a more mafic layer should be located beneath a highly feldspathic layer in the crust, it is the magnesian portion that comprises a magnesian anorthositic, upper crust and a magnesian troctolitic, lower crust, and the ferroan portion that is formed by a ferroan anorthositic, upper crust and a ferroan noritic, lower crust (Fig. 3).

A provenance of the southern nearside FHT for the FAN and a possible origin of the northern farside FHT for the MAN and ST in Dhofar 489 further suggest that the ferroan portion resides on the southern nearside and the magnesian portion resides on the northern farside (Fig. 3). The proposed dichotomous crust composition of the two hemispheres is remarkably consistent with the observed asymmetric surface composition of the FHT and crust stratigraphy inferred from remote-sensing studies. Thus, the new crust model with asymmetric composition and stratigraphy, based on the integrated results of the remote-sensing and sample studies, may demonstrate the early crustal configuration.

It should be noted that the asymmetric crust composition proposed above is based on the ground truth from pin-point sites, which are Apollo 16 landing site for the southern nearside FHT and a source region of the lunar meteorite Dhofar 489 , somewhere in the northern farside FHT. Global distributions of $\mathrm{mg \#}$ and rock types of the underlying feldspathic crust beneath the FHT are not well known. Upon acquisition of additional samples and orbital data in near future, the feasibility of this model will be evaluated, and further diversity may need to be incorporated.

\section{Origin and Evolution of the Lunar Crust}

The currently observed surface composition of the FHT represents the combined effects of magma ocean crystallization, post-magma-ocean magmatism and subsequent impact cratering events. In this section, we discuss the origin of the observed asymmetric composition of the FHT in relation to the proposed asymmetric crust composition, $\varepsilon_{\mathrm{Nd}}$ constraint, and resurfacing effects by the SPA basin formation.

\subsection{Asymmetric crystallization of the magma ocean}

For the origin of the crust with an asymmetric composition, one must assume an asymmetric crystallization of a magma ocean. The variations in rock types and compositions in the nearside crust-farside crust can be produced through differentiation of a single magma ocean as a result of a common liquid line of descent in a forsterite $\left(\mathrm{Mg}_{2} \mathrm{SiO}_{4}\right)$-anorthite $\left(\mathrm{CaAl}_{2} \mathrm{Si}_{2} \mathrm{O}_{8}\right)$-silica $\left(\mathrm{SiO}_{2}\right)$ system (e.g. Hess, 1989). Along the liquid line of descent, crystallization of olivine drives the residual liquid toward the olivine-plagioclase cotectic, leaving Mg-rich dunite cumulates probably sunken at the bottom of the magma ocean. Olivine and plagioclase accumulates as troctolites. The crystallization of olivine and plagioclase subsequently drives the liquids toward the orthopyroxene-olivineplagioclase peritectic, and the crystallization of olivine eventually ceases at the peritectic point. Liquids further proceed along the orthopyroxene-plagioclase cotectic toward the eutectic, generating norites. Based on the normal cumulate sequence (dunite) $\rightarrow$ troctolite $\rightarrow$ norite combined with a decrease in mg\# as magmatic differentiation proceeds, the troctolitic farside crust likely crystallized prior to the noritic nearside crust. The lithologies comprising the global crust (MAN, FAN, troctolitic anorthosite, noritic anorthosite) are feldspathic, and they probably formed as floated cumulates within the magma ocean. Because the MAN and FAN are extremely feldspathic, and thus less dense than the troctolitic anorthosite and the noritic anorthosite, respectively, they may constitute the upper portion of the farside crust and nearside crust. The farside crust may represent the earlier differentiation product of the magma ocean, and the nearside crust may be the later differentiate in the petrologic viewpoint (Fig. 4(a)). This interpretation is consistent with the presence of the PKT on the nearside, which probably represents the later or the last differentiate of a magma ocean (Fig. 5).

Although the compositional discrepancy of the nearsidefarside crust may be explained by different degrees of magmatic differentiation, it can not be determined whether the magma ocean on the farside cooled earlier or the earlier crystallizing components were mechanically assembled on the farside. The former case requires a difference in the thermal condition between the nearside and the farside, such as radiant heat from the Earth, tidal forces generated by the gravitational field of the Earth or impact flux (e.g. Wasson and Warren, 1980). Note that the thermal condition in the early history of the Moon should have been distinct relative to that of today because of the orbital evolution of the Moon (i.e. the Moon-Earth distance and the eccentricity of the lunar orbit) (e.g. Binder, 1978, 1982; Ryder, 2002; Garrick-Bethell et al., 2006). In the latter case, some mechanism to accumulate the early-crystallizing component on the farside needs to be considered, since a simple convection seems unlikely to contribute a large-scale lateral migration across the hemispheres (Loper and Werner, 2002). 


\section{(a) Asymmetric crystallization of a magma ocean}

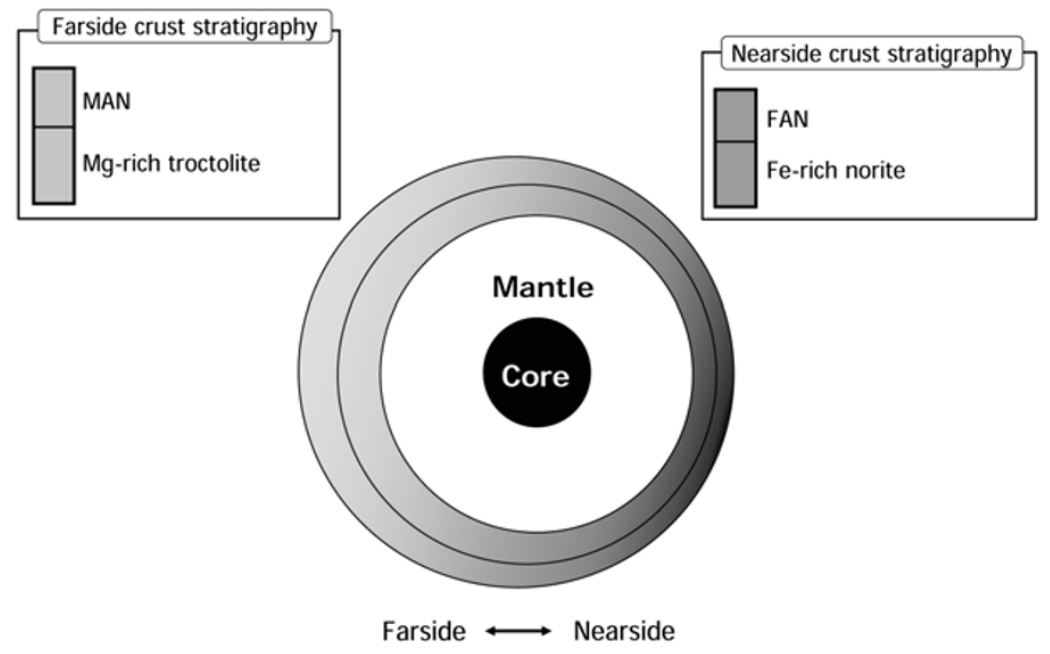

(b) Crust formed from a magma ocean and a magma sea

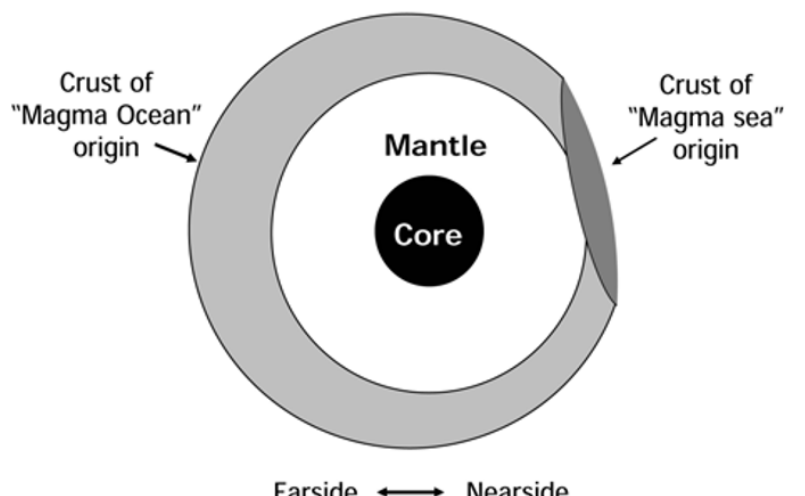

(c) SPA ejecta on the farside crust

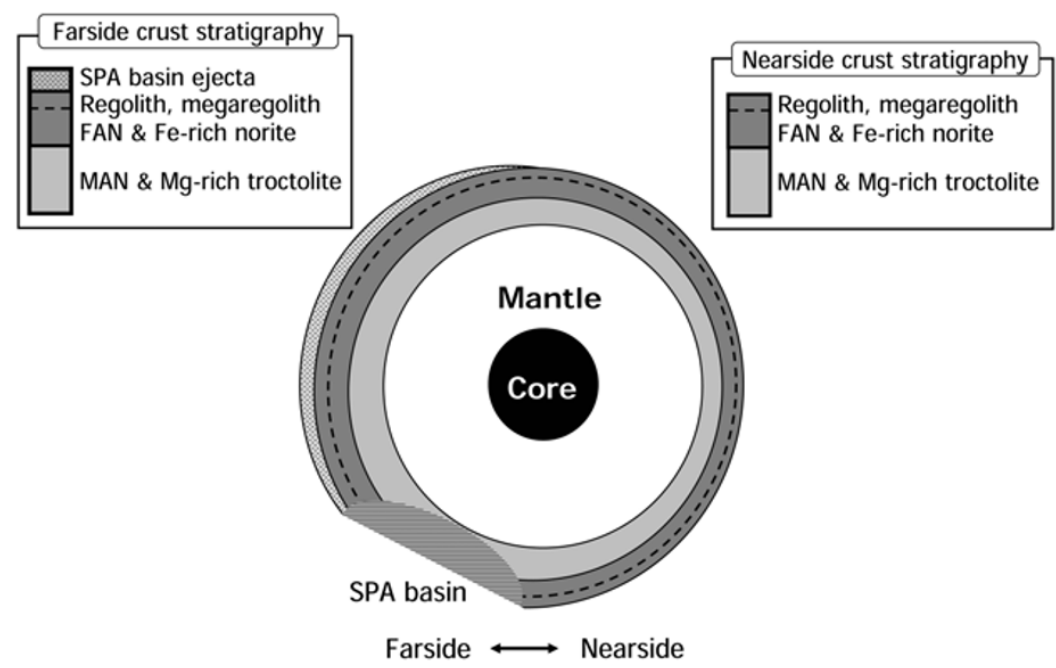

Fig. 4. Possible origins of asymmetric compositions of the FHT. Thickness of the crust, mantle and core is schematic. In order to clarify differences of crustal stratigraphy and compositional variation among the three cases, the crust is emphasized with greater thickness than that in Fig. 5. (a) A case for asymmetric crystallization of a magma ocean. The present composition of the FHT corresponds to an asymmetric composition of the initial crust generated during crystallization of a magma ocean. (b) A case for feldspathic crusts generated from a primordial magma ocean and from a secondary magma sea. While Apollo 16 FAN with positive $\varepsilon_{\mathrm{Nd}}$ values likely formed in a magma sea which was generated by remelting of a mantle cumulate of a magma ocean, a feldspathic rock in a lunar meteorite Yamato- 86032 with a positive $\varepsilon_{\mathrm{Nd}}$ value is probably derived from a magma ocean. Neither the chemical composition of the crusts originated from a magma ocean and a magma sea, nor a spatial/temporal relation between the crusts of different origins nor a mechanism of magma-sea formation can be constrained at this point. (c) A case for resurfacing by SPA ejecta on a homogeneous crust with a Fe-rich upper layer and a Mg-rich lower layer. The northern farside FHT is largely covered by deep-seated Mg-rich crust materials during the SPA basin formation. 


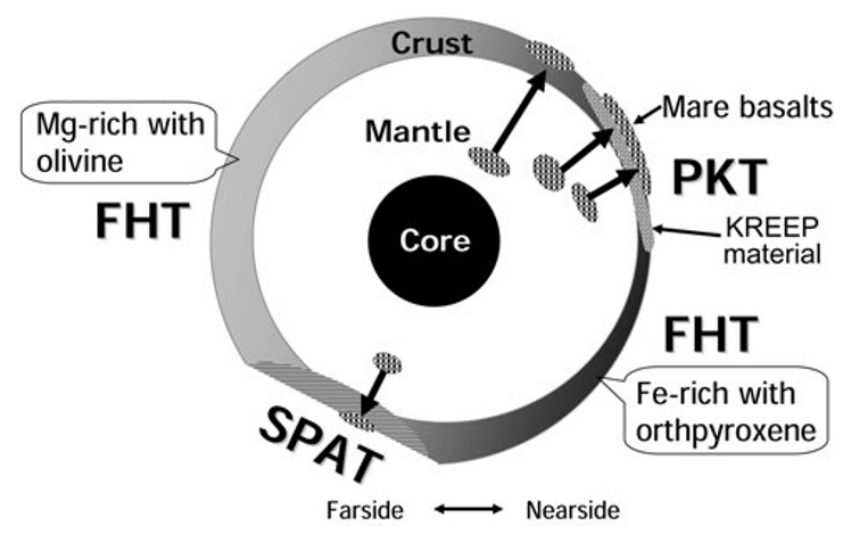

Fig. 5. Hypothetical cross section of the Moon to illustrate an asymmetric crust composition, stratigraphy and thickness in conjunction with the three terranes and mare basalt distribution. The thickness of the crust, mantle and core is schematic. Although it is generally assumed that a KREEP-rich magma-ocean residue is present at the crust-mantle boundary-at least in the PKT region - an origin of the PKT and its relation to the KREEP materials are still under debate. Because vertical distribution of KREEP materials are not well known, the distribution of the KREEP materials illustrated here is highly schematic. When a proposed asymmetric magma-ocean crystallization is assumed, the nearside likely represents the later differentiation of a magma ocean compared to the farside, with a more Fe-rich, pyroxene-rich composition and the presence of the last dreg of a magma ocean (PKT). Although a continuous variation in crustal composition from a magnesian, troctolitic farside to a ferroan, noritic nearside is tentatively postulated, a global distribution of $\mathrm{mg \#}$ and rock types on the FHT and the feldspathic crust are not well understood. FHT: the Feldspathic Highland Terrane, SPA: the South Pole-Aitken Terrane; PKT: the Procellarum KREEP Terrane.

Further, the current assumption that the synchronous rotation of the Moon was achieved at the very beginning of the Moon's history is uncertain. Morota and Furumoto (2003) proposed that the currently observed nearside-farside asymmetry, such as density of the basin-scale craters and crustal thickness, is a consequence of different impact energy or the impact velocity between the leading side and the trailing side of the Moon in its orbital motion. They suggested that the current nearside could be the leading side, and the current farside be the trailing side. Hence, the origin and the mechanism of the asymmetric crystallization of the magma ocean are matters of debate. Determining mg\# and mineralogical distribution of the global FHT surface will enable us to further explore modes and mechanisms of magma ocean crystallization.

\subsection{Post-magma-ocean origin}

In contrast with a magma-ocean origin for the crust, nonmagma-ocean origins have also been proposed. One model is proposed to account for the $\varepsilon_{\mathrm{Nd}}$ issue, as discussed in Section 4.3. In order to explain the positive $\varepsilon_{\mathrm{Nd}}$ value for the Apollo 16 FAN (Borg et al., 1999) and the negative $\varepsilon_{\mathrm{Nd}}$ value for the anorthositic clast in Yamato-86032, possibly from farside (Nyquist et al., 2006), a primordial magma ocean and a post-magma ocean remelting of mafic cumulates confined to the nearside, such as "magma sea" (Nyquist et al., 2006), are both required (Fig. 4(b)). A feldspathic crust generated from the secondary magma sea on the nearside might have been possibly more differentiated and more Fe-rich, relative to the initial crust crystallized from the magma ocean. However, because this hypothesis is based solely on the variations in $\mathrm{Sm}-\mathrm{Nd}$ isotopic composition in the limited feldspathic samples, it can not be readily linked with variations of chemical composition in the global FHT. Neither the chemical composition of crusts originated from a magma ocean and a magma sea, nor a spatial/temporal relation between the crusts of different origins nor a mechanism of magma-sea formation can be constrained at this point. The $\varepsilon_{\mathrm{Nd}}$ values of the MAN and ST of Dhofar 489 from the farside and the $\mathrm{Mg \#}$ distribution of the global FHT are the keys to justify the feasibility of this model.

If it is assumed that the nearside FHT and the PKT are the differentiated product from the magma sea, another origin of KREEP, which has been generally considered to be the last dregs of the magma ocean, may arise. However, the origin of KREEP can not be further discussed within the framework of a poorly constrained magma sea at this point.

Based on the results of melting experiments, Longhi (2003) proposed that FAN formed by remelting after solidification of a primordial magma ocean. In his model, a mafic-rich crust was originally generated during the rapid crystallization of the magma ocean and, subsequently, FAN formed by overturning and melting mafic cumulates from the magma ocean. The model can resolve difficulties in generating the FAN from a magma ocean (Haskin et al., 1981) and account for the high modal abundance of plagioclase of the FAN. Significantly, this post-magma-ocean origin for FAN satisfies constraints both from the Sm-Nd isotopic composition of FAN and phase equilibria. Thus, this model should be placed among magma ocean models as a working hypothesis, especially since it also can explain some possible origins of the crustal asymmetry.

\subsection{Resurfacing by SPA basin formation}

Large craters/basins on the Moon indicate that the early lunar crust was subjected to extensive excavation and mixing, both laterally and vertically. Studies of the crustal structure of Clementine gravity and topography suggest that the arc of elevated topography and thickened crust surrounding the SPA to the northern farside was a consequence of the oblique impact of the SPA (Neumann et al., 1996). Thus, it is highly likely that the SPA basin ejecta were mainly responsible for producing the surface composition and the observed crustal stratigraphy of the farside FHT. The lack of feldspathic materials within the SPA basin implies that a feldspathic upper crust was effectively removed from the interior of the SPA. A highly feldspathic region with an extremely low $\mathrm{FeO}(<2.5 \mathrm{wt} \%)$ occurs on the northern portion of the farside $100^{\circ} \mathrm{E}$ to $100^{\circ} \mathrm{W}$ and $40^{\circ} \mathrm{N}$ to $70^{\circ} \mathrm{N}$ (Hawke et al., 2003).

If the resurfacing effect by the SPA basin formation is the most dominant factor determining the present surface composition, the proposed asymmetric crust composition is not the only case to generate the asymmetric surface composition. When it is assumed that an initial feldspathic crust has a homogeneous composition with a ferroan upper layer and a magnesian lower layer (Korotev et al., 2003), the Mgrich deeper crustal materials could have been excavated by the SPA impact and distributed across the northern farside FHT over the Fe-rich upper crust (Fig. 4(c)). Accordingly, the observed asymmetric surface composition of the FHT 
can be generated from the initial crust with a globally uniform composition. This scenario also works for the case of the asymmetric crust composition. The SPA ejecta distribution to the northern farside highland would not have greatly changed the asymmetric compositional variation of the initial crust.

The mineralogical contrast between the SPA basin and the farside highland is currently open to debate. The nonmare mafic lithology across the SPA basin is mostly noritic or noritic anorthosite (Pieters et al., 2001; Lucey, 2004). On the other hand, the farside feldspathic highland is troctolitic anorthositic (Lucey, 2004). Based on the estimated transient cavity (>1000 km in diameter) (Spudis et al., 1994), the entire crustal column should have been excavated on the SPA impact target site. The pervasive noritic materials within the SPA basin may represent the composition of the impact melt deposits as a result of partial or total melting of the crust of the target site. The lateral and vertical distribution of the SPA ejecta on the farside FHT deduced from the detailed mineralogy and $\mathrm{mg \#}$ distribution on the farside FHT will enable us to assess the resurfacing effect by the SPA basin formation and to understand the origin of the SPAT.

Multiple basins should have resurfaced the nearside as well. Among the nearside basins, the Procellarum basin is the largest, with a diameter (putatively $2300 \mathrm{~km}$ ) close to that of the SPA basin. Although its origin is under debate (e.g. Schultz, 2007), the giant Procellarum basin should have been highly asymmetrical and with an elevated topography of the highlands south of Serenitatis and Nectaris, if it existed (Neumann et al., 1996). Thus, it would have excavated and distributed the entire crustal column on the southwestern nearside. The regolith of the nearside FHT sampled at the Apollo 16 site includes feldspathic components which were likely formed by the Pre-Imbrium impact events (Korotev, 1997). These "prebasin" feldspathic components are generally more magnesian than FAN. Thus, the magnesian feldspathic components may be prevalent in the feldspathic crust at depth, as proposed by Korotev et al. (2006). Or they may be possibly related to mantle materials, because the crustal thickness is approximately $13-17 \mathrm{~km}$ thinner than that of the farside (Wieczorek and Zuber, 2001). The net effect of basin formation on crustal evolution remains an open question until the compositions and thickness of the upper crust and the lower crust are determined.

\section{Future Studies to Resolve Unanswered Ques- tions}

Orbital geochemical investigations and studies of lunar meteorites have advanced our understanding of the composition and evolution of the lunar crust, but at the same time they have uncovered the complexity in the composition, structure and origin of the crust, thereby generating further questions to be resolved. Key questions that need to be defined in order to correctly understand the observed hemispheric dichotomy in the surface composition of the FHT and to assess the feasibility of the proposed asymmetrical crust model are (1) mg\#, (2) rock types and (3) mineral compositions of the FHT and the SPAT. These data are extremely important for assessing whether the chemical and mineralogical compositions of the surface of the FHT and the underlying crust continuously varies on a global scale or whether it differs as local varieties and for understanding how the SPA ejecta modified the surface composition of the farside FHT. Accordingly, these data will provide us with the ideas of how the hemispheric asymmetry of the lunar crustal composition was generated, how the magma ocean crystallized, and how the post-magma-ocean processes are involved in the lunar crustal evolution.

The new data with high resolution and high precision to be provided by the KAGUYA (SELENE) mission will answer these questions and contribute to an improved understanding of lunar crustal genesis. KAGUYA, with a mapping orbit of approximately $100 \mathrm{~km}$, will provide us with high spectral-resolution reflectance data and major/trace element distribution of the global lunar surface. The Multiband Imager (MI) will collect reflectance data of five bands $(415,750,900,950,1000 \mathrm{~nm})$ in the visible spectrum with a spatial resolution of $20 \mathrm{~m} / \mathrm{pixel}$ and of four bands $(1000$, $1050,1250,1550 \mathrm{~nm})$ in near-infrared spectrum with a spatial resolution of $62 \mathrm{~m} / \mathrm{pixel}$. The Spectral Profiler (SP) will obtain reflectance data from 500 to $2600 \mathrm{~nm}$ with a 6to $8-\mathrm{nm}$ spectral resolution and a $500-\mathrm{m}$ spatial resolution. These data will enable us to more uniquely and accurately determine the mineralogy (modal abundance of minerals and mineral composition) of the lunar surface. The Terrane Camera (TC) will carry out geologic mapping with a spatial resolution of $10 \mathrm{~m} /$ pixel. Concentrations of major elements, such as $\mathrm{Fe}, \mathrm{Mg}, \mathrm{Ca}$ and $\mathrm{Al}$, on the surface will be acquired by the X-ray fluorescence spectrometer (XRS) with spatial resolution of approximately $30 \mathrm{~km}$. The gamma-ray spectrometer (GRS) with a sixfold better energy resolution than the Lunar Prospector will survey the major element abundances as well as trace element abundances. Globescale gravity tracking by the Relay Satellite (RSAT) and the VLBI radio source (VRAD) will be able to constrain the global crustal thickness more accurately.

While remote-sensing studies provide us with the global mineralogy and chemistry, sample studies are also critical to understand the respective rock types occurring in the crust and to obtain major, minor and trace-element abundances and isotopic compositions of the bulk rocks and the minerals. The latest studies of meteorites paired with Dhofar 489 indicated broader variations of mineral compositions and rock textures than previously observed (Arai et al., 2007). Mineralogical and isotopic investigations on Dhofar 489 and its siblings are required to gain a proper understanding of the compositional variations and the petrogenesis of the farside crust. The global mineralogical, elemental and gravity data of KAGUYA combined with further studies of lunar meteorites will significantly improve our understanding of lunar crustal genesis.

\section{Conclusions}

It has been revealed that the earlier models of lunar crustal formation as a simple flotation of ferroan anorthosite are not consistent with the diverse crustal composition suggested by feldspathic lunar meteorites and granulites in the Apollo samples. Based on the integrated results of recent studies of lunar meteorites and global chemical and miner- 
alogical maps, a new model of the lunar crust is proposed. The model includes a ferroan, noritic nearside crust and a magnesian, troctolitic farside crust. Asymmetric crystallization of a primordial magma ocean can be one possibility by which a crust with an asymmetric composition was produced, although the mechanism of this model needs to be further investigated. A post-magma-ocean origin for a portion of the lunar crust is also possible as this would account for the positive $\varepsilon_{\mathrm{Nd}}$ value for the FAN and the phase equilibria. The formation of giant basins, such as the SPA basin, may have a significant effect on the resurfacing of the early lunar crust. Thus, the observed surface composition of the FHT represents the combined results of magma ocean crystallization, post-magma-ocean magmatism and resurfacing by basin formation. The $\mathrm{Mg} /(\mathrm{Mg}+\mathrm{Fe})$ ratios, rock types and mineral compositions of the global FHT and the SPAT to be obtained from the KAGUYA mission, coupled with further mineralogical and isotopic studies of lunar meteorites, will assess the feasibility of the proposed crust model and improve our understanding of lunar crustal genesis and evolution.

Acknowledgments. We thank L. E. Nyquist and R. L. Korotev for insightful and constructive reviews. We also thank B. Ray Hawke, K. Kuramoto, S. Sugita and K. Saiki for productive discussions. This work was supported by the JSPS Research Fellowships for Young Scientists, and NIPR, Research Project Funds, P-8 (Evolution of the early Solar System Materials).

\section{References}

Arai, T., H. Takeda, A. Yamaguchi, and M. Ohtake, Lithology of lunar farside crust, Meteor. Planet. Sci., 42, A14, 2007.

Binder, A. B., On fission and the devolatilization of a Moon of fission origin, Earth Planet. Sci. Lett., 41, 381-385, 1978.

Binder, A. B., The Moon: Its figure and orbital evolution, Geophys. Res. Lett., 9, 33-36, 1982

Borg, L., M. Norman, L. Nyquist, D. Bogard, G. Snyder, L. Taylor, and M. Lindstrom, Isotopic studies of ferroan anorthosite 62236: A young lunar crustal rock from a light rare-earth-element-depleted source, Geochim. Cosmochim. Acta, 63, 2679-2691, 1999.

Bussey, D. B. J. and P. D. Spudis, Compositional studies of the Orientale, Humorum, Nectaris, and Crisium lunar basins, J. Geophys. Res., 105(E2), 4235-4243, 2000.

Canup, R. M., Simulation of a late lunar-forming impact, Icarus, 168, 433456, 2004.

Carlson, R. W. and G. W. Lugmair, The age of ferroan anorthosite 60025: oldest crust on a young Moon?, Earth Planet. Sci. Lett., 90, 119-130, 1988.

Dowty, E., K. Keil, and M. Printz, Igneous rocks from Apollo 16 rake samples, Lunar Sci., V, 174-176 (abstract), 1974.

Garrick-Bethell, I., J. Wisdom, and M. T. Zuber, Evidence for a past higheccentricity lunar orbit, Science, 313, 652-655, 2006.

Gillis, J. J., B. L. Jolliff, and R. L. Korotev, Lunar surface geochemistry: Global concentrations of $\mathrm{Th}, \mathrm{K}$, and $\mathrm{FeO}$ as derived from $\mathrm{Lu}-$ nar Prospector and Clementine, Geochim. Cosmochim. Acta, 63, 37913805, 2004.

Haskin, L. A., The Imbrium impact event and the thorium distribution at the lunar highlands surface, J. Geophys. Res., 103, 1679-1689, 1998.

Haskin, L. A., M. M. Lindstrom, and P. A. Salpas, Some observations on compositional characteristics of lunar anorthosites, Lunar Planet. Sci., XII, 304-305 (abstract), 1981.

Hawke, B. R., C. A. Peterson, D. T. Blewett, D. B. J. Bussey, P. G. Lucey, G. J. Taylor, and P. D. Spudis, Distribution and mode of occurrence of lunar anorthosite, J. Geophys. Res., 108(E6), 5050, 2003.

Hess, P. C., In Origins of igneous rocks, Harvard University Press, Cambridge, 1989.

Hess, P. C. and E. M. Parmentier, A model for the thermal and chemical evolution of the Moon's interior: Implications for the onset of mare volcanism, Earth Planet. Sci. Lett., 134, 501-514, 1995.
Hess, P. C. and E. M. Parmentier, Thermal evolution of a thicker KREEP liquid layer, J. Geophys. Res., 106(E1), 28,023-28,032, 2001.

Jacobsen, S. B. and G. J. Wasserburg, SM-Nd isotopic evolution of chondrites and achondrites, II, Earth Planet. Sci. Lett., 67, 137-150, 1984.

Jolliff, B. L., J. J. Gillis, L. Haskin, R. L. Korotev, and M. A. Wieczorek, Major lunar crustal terranes: Surface expressions and crustal-mantle origins, J. Geophys. Res., 105, 4197-4216, 2000.

Korotev, R. L., Some things we can infer about the moon from the composition of the Apollo 16 regolith, Meteor. Planet. Sci., 32, 447-478, 1997.

Korotev, R. L., The great lunar hot spot and the composition and origin of the Apollo mafic ("LKFM") impact-melt breccias, J. Geophys. Res., 105, 4317-4345, 2000.

Korotev, R. L. and R. A. Zeigler, Keeping up with the lunar meteorites, Lunar Planet. Sci., 38, Abstract 1340, 2007.

Korotev, R. L., B. L. Jolliff, R. A. Zeigler, J. J. Gillis, and L. A. Haskin, Feldspathic lunar meteorites and their implications for compositional remote sensing of the lunar surface and the composition of the lunar crust, Geochim. Cosmochim. Acta, 67, 4895-4923, 2003.

Korotev, R. L., R. A. Zeigler, and B. L. Jolliff, Feldspathic lunar meteorites Pecora Escarpment 02007 and Dhofar 489: Contamination of the surface of the lunar highlands by post-basin impacts, Geochim. Cosmochim. Acta, 70, 5935-5956, 2006.

Lawrence, D. J., R. C. Elphic, W. C. Feldman, T. H. Prettyman, O. Gasnault, and S. Maurice, Small-area thorium features on the lunar surface, J. Geophys. Res., 108(E9), 5102, 2003.

Lindstrom, M. M. and D. J. Lindstrom, Lunar granulites and their precursor anorthositic norites of the early lunar crust, Proc. Lunar Planet. Sci. Conf., 12B, 305-322, 1986.

Longhi, J., A new view of lunar ferroan anorthosites: Postmagma ocean petrogenesis, J. Geophys. Res., 108(E8), 5083, doi:10.1029/ 2002JE001941, 2003.

Longhi, J. and J. D. Ashwal, Two-sage model for lunar and terrestrial anorthosites: petrogenesis without a magma ocean, Proc. $15^{\text {th }}$ Lunar Sci. Conf., C571-C584, 1985.

Loper, D. E. and C. L. Werner, On lunar asymmetries 1. Tilted convection and crustal asymmetry, J. Geophys. Res., 107(E6), 5046, 10.1029/ 2000JE001441, 2002.

Lucey, P. G., Mineral maps of the Moon, Geophys. Res. Lett., 31, L08701, 2004.

Lucey, P. G. and J. Cahill, Magnesian rock types in the lunar highlands: Remote sensing using data from Lunar Prospector and Clementine, Lunar Planet. Sci., 37, Abstract 1660, 2006.

Lucey, P. G., G. J. Taylor, and E. Malaret, Abundance and distribution of iron on the Moon, Science, 268, 1150-1153, 1995.

Lucey, P. G., D. T. Blewett, and B. R. Hawke, Mapping the FeO and $\mathrm{TiO}_{2}$ content of the lunar surface with multispectral imagery, J. Geophys. Res., 103, 3679-3699, 1998.

Lucey, P. G., D. T. Blewett, G. J. Taylor, and B. R. Hawke, Lunar iron and titanium abundance algorithms based on final processing of Clementine ultraviolet-visible images, J. Geophys. Res., 105, 20377-20386, 2000.

Lucey, P., R. L. Korotev, J. J. Gillis, L. A. Taylor, D. Lawrence, B. A. Campbell, R. Elphic, B. Feldman, L. L. Hood, D. Hunten, M. Mendillo, S. Noble, J. J. Papike, R. C. Reedy, S. Lawson, T. Prettyman, O. Gasnault, and S. Maurice, Understanding the lunar surface and space-Moon interactions, in New View of the Moon, Reviews in Mineralogy \& Geochemistry, Vol. 60, edited by B. L. Jolliff, M. A. Wieczorek, C. K. Shearer, and C. R. Neal, 83-219, Mineralogical Society of America, 2006.

Ma, M.-S., R. A. Schmitt, G. J. Taylor, R. D. Warner, and K. Keil, Chemical and petrographic study of spinel troctolite in 67435: Implication for the origin of Mg-rich plutonic rocks, Lunar Planet. Sci., 12, 640-642 (abstract), 1981.

Morota, T. and M. Furumoto, Asymmetrical distribution of rayed craters of the Moon, Earth Planet. Sci. Lett., 206, 315-323, 2003.

Neumann, G. A., M. T. Zuber, D. E. Smith, and F. G. Limoine, The lunar crust: Global structure and signature of major basins, J. Geophys. Res., 101, 16,841-16,843, 1996.

Norman, M. D., L. E. Borg, L. E. Nyquist, and D. D. Bogard, Crystallization age and impact resetting of ancient lunar crust from the Descartes terrane, in The Moon Beyond 2002: Next steps in Lunar Science and Exploration, abstract 3028, edited by D. J. Lawrence and M. B. Duke, The Lunar and Planetary Institute, Houston, 2002.

Nyquist, R. L., Lunar Rb-Sr chronology, Phys. Chem. Earth, 10, 103-142, 1977.

Nyquist, R. L., D. Bogard, A. Yamaguchi, C.-Y. Shih, Y. Karouji, M. 
Ebihara, Y. Reese, D. Garrison, G. McKay, and H. Takeda, Feldspathic clasts in Yamato-86032: Remnants of the lunar crust with implications for its formation and impact history, Geochim. Cosmochim. Acta, 70, 5990-6015, 2006.

Papike, J. J., G. Ryder, and C. K. Shearer, Lunar samples, in Planetary Materials, Reviews in Mineralogy \& Geochemistry, Vol. 36, edited by J. J. Papike, 5-1-5-234, Mineralogical Society of America, 1998.

Parmentier, E. M., S. Zhong, and M. T. Zuber, Gravitational differentiation due to initial chemical stratification: origin of lunar asymmetry by the creep of dense KREEP?, Earth Planet. Sci. Lett., 201, 473-480, 2002.

Pieters, C. M., J. W. Head III, L. Gaddis, and M. Duke, Rock types of South Pole-Aitkens basin and extent of basaltic volcanism, J. Geophys. Res., 106, 28,001-28,022, 2001.

Ryder, G., Lunar ferroan anorthosites and mare basalt sources: The mixed connection, Geophys. Res. Lett., 18, 2065-2068, 1991.

Ryder, G., Mass flux in the ancient Earth-Moon system and benign implications for the origin of life on Earth, J. Geophys. Res., 107, 1-14, 2002.

Schultz, P. H., A possible link between Procellarum and the South-PoleAitken basin, Lunar Planet. Sci., XXXVIII, Abstract 1839, 2007.

Shirley, D. N. A., partially molten magma ocean, Proc. $13^{\text {th }}$ Lunar Planet. Sci. Conf., A519-A527, 1983.

Snyder, G. A., L. A. Taylor, and C. R. Neil, A chemical model for generating the sources of mare basalts: Combined equilibrium and fractional crystallization of the lunar magmasphere, Geochim. Cosmochim. Acta, 56, 3809-3823, 1992.

Spudis, P. D., R. A. Reese, and J. J. Gillis, Ancient multiring basins on the Moon revealed by Clementine laser altimetry, Science, 266, 1848-1851, 1994.

Takeda, H., A. Yamaguchi, D. D. Bogard, Y. Karouji, M. Ebihara, M. Ohtake, K. Saiki, and T. Arai, Magnesian anorthosites and a deep crustal rock from the farside crust of the moon, Earth Planet. Sci. Lett., 247, 171-184, 2006.

Taylor, G. J., P. Warren, G. Ryder, J. Delano, C. Pieters, and G. Lofgren, Lunar Rocks, in Lunar Sourcebook: A Users Guide to the Moon, edited by Heiken, G. H., D. T. Vaniman, and B. M. French, 183-284, Cambridge University Press, 1991.

Taylor, S. R., In Planetary Science: A Lunar Perspective, p. 481, Lunar and Planet. Inst., Houston, Tex., 1982.

Tera, F., D. A. Papanastassiou, and G. J. Wasserburg, Isotopic evidence for a terminal cataclysm, Earth Planet. Sci. Lett., 22, 1-22, 1974.

Tompkins, S. and C. M. Pieters, Mineralogy of the lunar crust: Results from Clementine, Meteor. Planet. Sci., 34, 25-41, 1999.

Walker, D., Lunar and terrestrial crustal formation, Proc. $14^{\text {th }}$ Lunar Planet. Sci. Conf., B17-B25, 1983.

Warner, J. L., W. C. Phinney, C. E. Bickel, and C. H. Simonds, Feldspathic granulitic impactites and pre-final bombardment lunar evolution, Proc. $8^{\text {th }}$ Lunar Sci. Conf., 2051-2066, 1977.

Warren, P. H., The magma ocean concept and lunar evolution, Ann. Rev. Earth Planet. Sci., 13, 201-240, 1985.

Warren, P. H., Lunar anorthosites and the magma-ocean plagioclaseflotation hypothesis: Importance of $\mathrm{FeO}$ enrichment in the parent magma, Am. Miner., 75, 46-58, 1990.

Warren, P. H., A concise compilation of petrologic information on possibly pristine nonmare Moon rocks, Am. Miner., 78, 360-376, 1993.

Warren, P. H., The Moon, in Meteorites, Comets, and Planets, editied by A. M. Davis, 559-599, Treatise on Geochemistry, Vol. 1, edited by H. D. Holland and K. K. Turekian, Elsevier-Pergamon, Oxford, 2004.

Warren, P. H. and J. T. Wasson, Pristine nonmare rocks and the nature of the lunar crust, Proc. $8^{\text {th }}$ Lunar Sci. Conf., 2215-2235, 1977.

Warren, P. H. and J. T. Wasson, Early lunar petrogenesis, oceanic and extraoceanic, in Proc. of the conference on the Lunar Highland Crust, 81-99, edited by R. B. Merill and J. J. Papike, Pergamon, New York, 1980

Wasson, J. T. and P. H. Warren, Contribution of the mantle to the lunar asymmetry, Icarus, 44, 752-771, 1980.

Wetherill, G. W., Nature and origin of basin-forming projectiles, in Multiring Basins, edited by P. Schultz and R. B. Merill, 1-18, Pergamon, New York, 1981 .

Wieczorek, M. A. and R. J. Phillips, The "Procellarum KREEP Terrane": Implications for mare volcanism and lunar evolution, J. Geophys. Res., 105, 20417-20420, 2000.

Wieczorek, M. A. and M. T. Zuber, The composition and origin of the lunar crust: Constraints from central peaks and crustal thickness modeling, Geophys. Res. Lett., 28, 4023-4026, 2001.

Wieczorek, M. A., B. L. Jolliff, A. Khan, M. E. Pritchard, B. P. Weiss, J. G. Williams, L. L. Hood, K. Righter, C. R. Neal, C. K. Shearer, I. S. McCallum, S. Tompkins, B. R. Hawke, C. Peterson, J. J. Gillis, and B. Bussey, The constitution and structure of the lunar interior, in New View of the Moon, Reviews in Mineralogy \& Geochemistry, Vol. 60, edited by B. L. Jolliff, M. A. Wieczorek, C. K. Shearer, and C. R. Neal, 221-364, Mineralogical Society of America, 2006.

Wood, J. A., Lunar petrogenesis in a well-stirred magma ocean, Proc. $6^{\text {th }}$ Lunar Sci. Conf., 2107-2130, 1975.

Zhong, S., E. M. Parmentier, and M. T. Zuber, A dynamic origin for the global asymmetry of lunar mare basalts, Earth Planet. Sci. Lett., 177, 131-140, 2000 .

T. Arai (e-mail: tomoko@nipr.ac.jp), H. Takeda, A. Yamaguchi, and M. Ohtake 